\title{
Note on an Unusual Specimen of Asterias rubens L.
}

\author{
By \\ Herbert 0. Bull, Ph.D., B.Sc., \\ The Dove Marine Laboratory, Cullercoats.
}

With 1 Figure in the Text.

A VERY small, globular Echinoderm was brought to the Dove Marine Laboratory in September, 1931. Its locality of capture is not known, but it is thought to have been brought in by a child who had collected it on the local rocks. The first impression was that of one of the flatter Echinoids. Examination revealed only characteristic Asteroid features. Figures 1, A and B, are photo-micrographs of the living specimen in seawater, taken on September 16th with a 4-in. objective. The following is a description made on the same date.

Test, globular, similar in shape to Echinus miliaris. Diameter, $9 \cdot 8 \mathrm{~mm}$., height $7 \cdot 2 \mathrm{~mm}$.

Oral surface. Mouth central, turning downwards-in the centre of a 5-radiate depression; the radii with no spines, but bearing a double row of large tube-feet in the grooves, each terminating in a well-defined sucking disc. Large plates overhung the mouth in each inter-radial area ; these could be opened or closed to a considerable extent and were well furnished with spines carrying one to three straight pedicellariæ. No indications of teeth or of any structure resembling an Echinoid peristome.

The oral surface passed insensibly into the ab-oral. Closer to the oral than to the ab-oral surface a narrow zone of small, irregular rectangular plates encircled the "test." These were richly provided with sessile straight pedicellariæ, but had no tube-feet.

Ab-oral surface. This was composed of irregularly-shaped plates with no signs of radial symmetry, no apical system, and no division into ambulacral or adambulacral areas. There were no spines or tubercles. An extensive system of pointed, extensible, delicate papulæ gave a characteristic appearance when fully extended. Most of the plates, especially the larger ones, had one or more paxillæ similar to those of Asterias rubens. Scattered pedicellariæ of both crossed and straight types were present. 


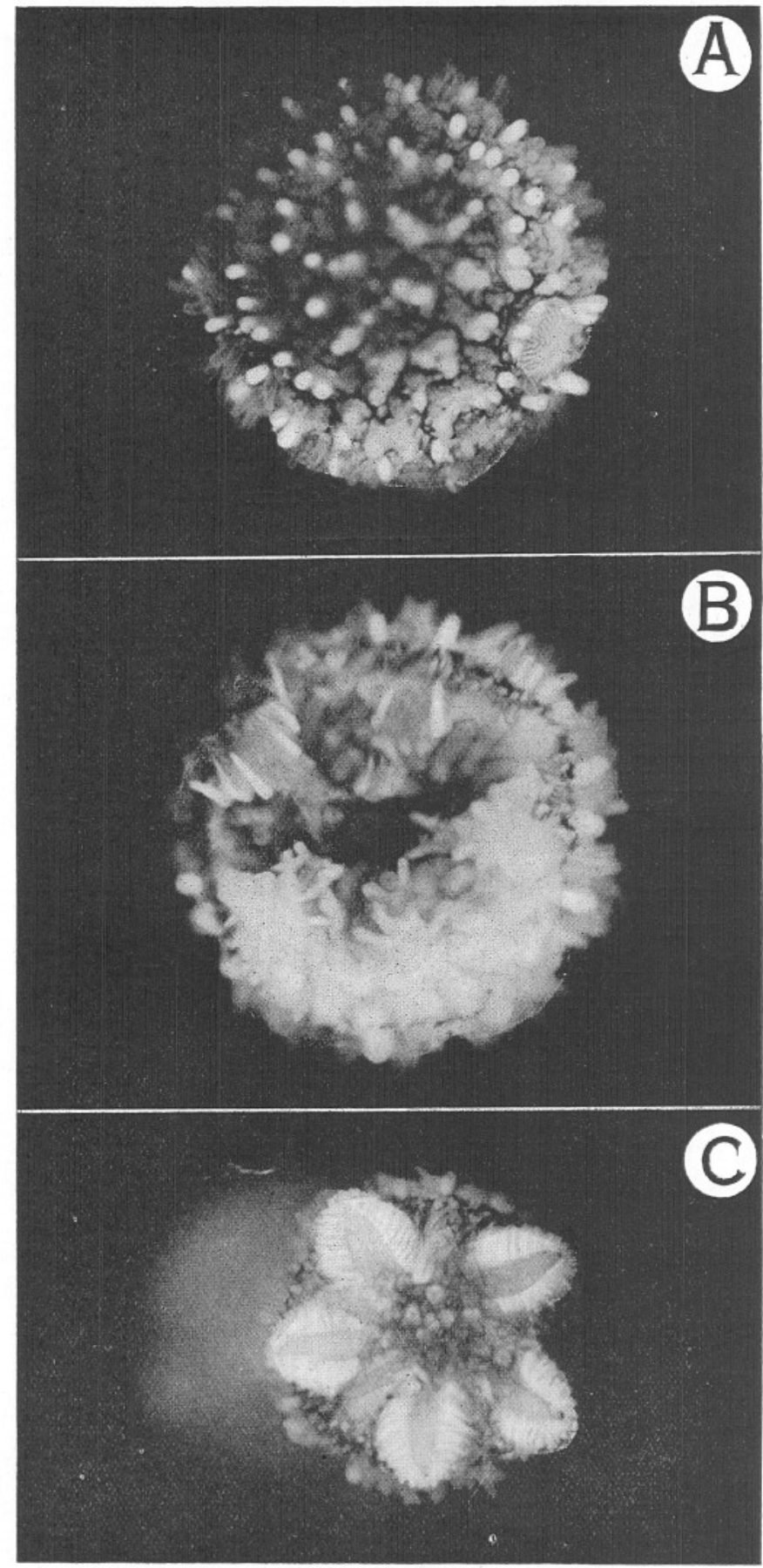

(A)

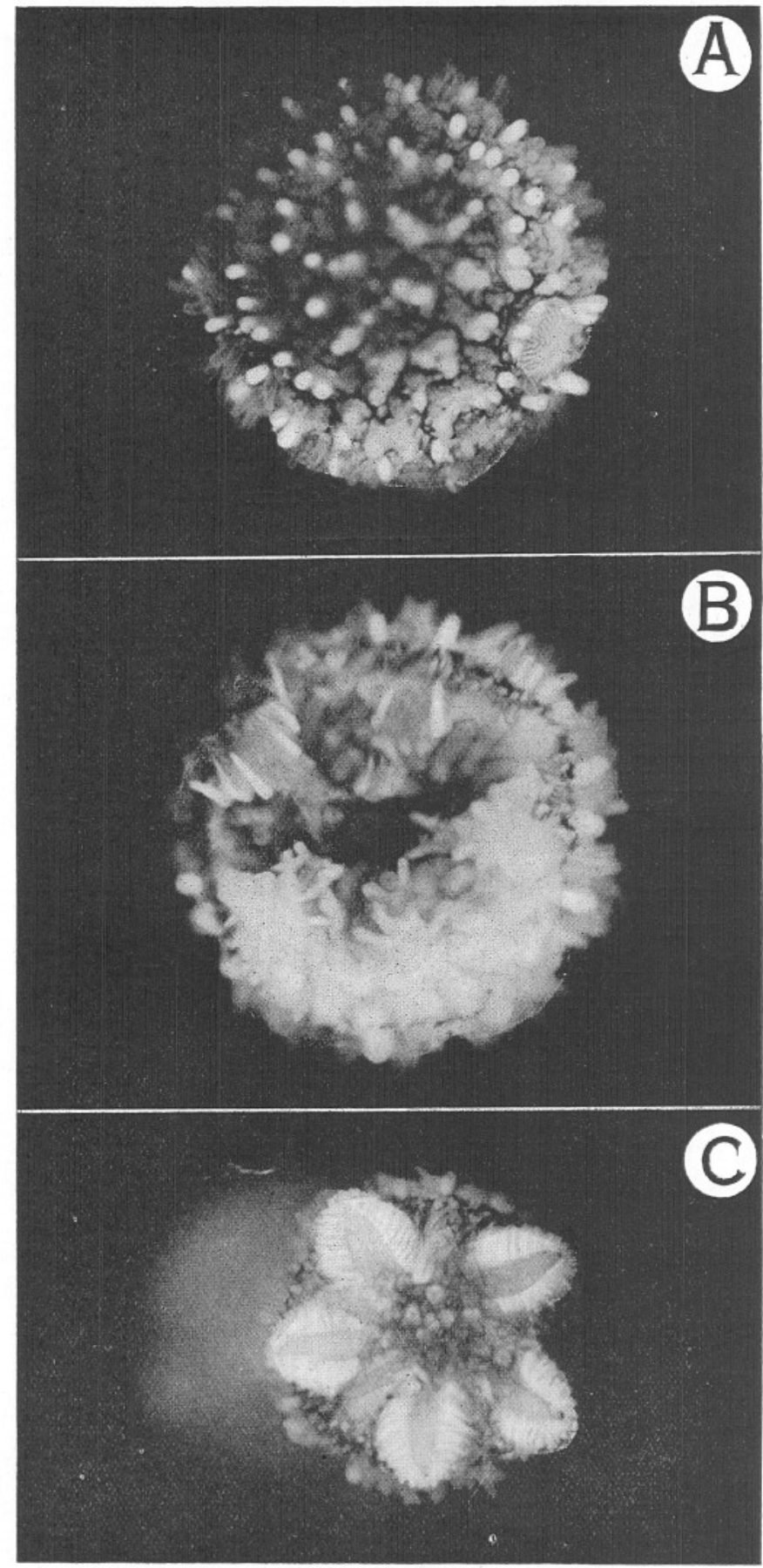

FIG. 1.-An unusual specimen of Asterias rubens. Photo-micrographs of the living animal in sea-water.
A. Sept. 16th, 1931. Ab-oral surface. $\times 5$
B.
do.
Oral surface.
$\times 5$.
C. Dec. 1st, 1931 .
Oral surface.
$\times 2$. 
A large and conspicuous madreporite was present, situated inter-radially, and a minute functional anus in the centre of this surface.

The colour of the plates was white with a tinge of pink; the margins of the plates outlined in brown. The madreporite was a bright rosy pink.

A large, eversible stomach was observed to be extruded for the capture of food.

The animal was clearly an Asteroid, in spite of its unusual form. It continued to live healthily in captivity. By September 30th the radial grooves had become extended outwards and dorsally (in an ab-oral direction). On October 11th these extensions measured $3-4 \mathrm{~mm}$. in length from the inner point of each inter-radial plate; ambulacral plates and spines were now clearly visible and a few very fine tube-feet had appeared in the extensions of the grooves. At the apex of the oral surface of each arm the red sensory spot was first noticed on this date. A number of attempts were made to obtain photographs of these stages, but none turned out sufficiently good to reproduce, owing to the extreme activity of the animal and to its habit of recurving the arms back close to the "test," so that focussing was impossible. The arms continued to grow and the animal to increase in girth without losing its characteristic spherical shape. Figure 1, C, was taken on December 1st, 1931. On this date, 10 weeks later than that when Figures 1, A and B, were taken, the "test" had a diameter of $18 \mathrm{~mm}$.; and a height of $15 \mathrm{~mm}$.; the arms had grown to 7-9 $\mathrm{mm}$. measured as before. On December 26th the animal crawled over its partition into the next tank where it was captured and eaten by a Solaster papposus during my absence.

There appears to be no way of deciding whether this specimen represents an interesting example of regeneration or an abnormal development. It would be of interest to speculate on the verdict of a systematist confronted with the specimen when it was first photographed but presented to him as a fossil. 
